\title{
Constructive properties of concrete being finely reinforced with polypropylene fibers
}

\author{
Inna Korneyeva ${ }^{1, *}$ \\ ${ }^{1}$ Irkutsk National Research Technical University, 664074, Lermontova str., 83, Irkutsk, Russia
}

\begin{abstract}
The paper presents results of the statistical generalization of experimental data on the strength and deformability of fiber-reinforced concrete with different levels of bulk dispersion reinforcement. The range of the optimal content of reinforcing elements is established according to the criteria for ensuring maximum crack resistance and strength of the matrix (concrete).
\end{abstract}

\section{Introduction}

According to modern concepts $[1,2,4]$, concrete refers to multicomponent systems, which determine the design drawback of which is the tendency to brittle failure. One of the technologically possible and economically feasible ways to reduce the likelihood of their brittle fracture is the introduction of dispersed reinforcing elements in the structure with increased tensile strength. As such, metal chips were most often used, which limited the use of fiber-reinforced concrete in terms of economic and energy feasibility. Mass production of plastics, including in the form of fibrous fibers of various diameters and strength, allow one to assume the possibility of their use as the reinforcing elements of concrete matrices. The choice of the determining parameters of macrosynthetic polypropylene fibers, their volume content, depending on the a priori of the tasks being set, constitute the main objective of this study.

\section{Methods and materials}

The basis of experimental research is based on the fundamental principles $[1,3,5,6]$, according to which the optimal levels of disperse reinforcement should be closely related to the determining structural parameters of concrete (matrix). That is, the diameter, length, degree of dispersion of reinforcing elements are determined by structural discontinuities of concrete (porosity, defects, etc.). In this case, it becomes possible to inhibit (suspend) the nascent cracks on the boundaries of the matrix and reinforcing elements and change the nature of the failure.

The starting materials used:

- Portland cement produced by the Angarskcement OJSC, with the tensile strength at bending $2.8 \mathrm{MPa}$, for compression $12.88 \mathrm{MPa}$;

\footnotetext{
*Corresponding author: pinus@istu.edu
} 
- Sand of local composition (Table 1);

- Rubble granite with a maximum grain size of $10 \mathrm{~mm}$;

- Polypropylene macrosynthetic fiber produced by the Technopoli-mer LLC, Irkutsk, Russia (Table 2).

Table 1. Granulometric composition of sand (according to GOST 8736-93).

\begin{tabular}{|l|c|c|c|c|c|c|}
\hline \multirow{2}{*}{ Balance } & \multicolumn{5}{|c|}{ Residues, \% by weight on sieves } & \multirow{2}{*}{$\begin{array}{c}\text { The size } \\
\text { module }\end{array}$} \\
\cline { 2 - 6 } & 2,5 & 1,25 & 0,63 & 0,315 & 0,16 & \multirow{2}{*}{$M_{c r}=2,02$} \\
\hline Private & 7,5 & 4 & 15 & 46 & 11,5 & \\
\hline Full & 7,5 & 11,5 & 26,5 & 72,5 & 84 & \\
\hline
\end{tabular}

Table 2. Parameters of reinforcing fibers (according to GOST 9550-81).

\begin{tabular}{|l|l|}
\hline Fiber & Polypropylene \\
\hline Initial cross-section of the sample, $\mathrm{mm}^{2}$ & 0.5 \\
\hline Tensile strength, MPa & 145.54 \\
\hline Relative elongation at maximum load, \% & 21.95 \\
\hline Modulus of elasticity, MPa & 2767 \\
\hline Durability at the conditional yield point, $\mathrm{MPa}$ & 38.5 \\
\hline Breaking strength, MPa & 140.9 \\
\hline Elongation at break, \% & 22.30 \\
\hline
\end{tabular}

As a matrix for the production of fiber concrete samples, concrete of the following composition was used: C: $\mathrm{S}: \mathrm{R}: \mathrm{P}=1: 1.42: 3.31: 0.55$ (at $\mathrm{C}=380 \mathrm{~kg} / \mathrm{m} 3$ ). The volume content of fiber of $55 \mathrm{~mm}$ was $0.9 ; 1.0 ; 1.25 \%$.

The preparation of fiber-concrete mixes was carried out in a laboratory concrete mixer forcing the following sequence of loading components: (a) first, sand, crushed stone, and half of the mixing water were mixed for 2 minutes, (b) then, while stirring, fibers, cement, and other half water were added until obtaining homogeneous mixtures.

To compact the mixtures in the molding process, a standard vibroplatform was used. The vibrating time, depending on the amount of fiber introduced, was $90 \pm 180 \mathrm{~s}$. From the prepared fiber-concrete mixes, prism samples of $100 \times 100 \times 400 \mathrm{~mm}$ were made. Each series consisted of 12 samples that were kept in molds for 3 days after concreting at a temperature of $20 \pm 2{ }^{\circ} \mathrm{C}$ under a protective film, then they were decompacted and stored until being tested in a normal hardening chamber at a temperature of $(20 \pm 2)^{\circ} \mathrm{C}$ and humidity of $(95$ \pm 5 )\% for 28 days. At the end of the planned period, an ultrasonic density calibration and an axial compression test. Loading of the samples during testing was carried out with deformation control at the universal Instron testing machine with a constant traversing speed of $0.004 \mathrm{~mm} / \mathrm{s}$. The testing equipment allowed in an automatic mode to record the stressstrain diagrams, the modulus of elasticity and the fracture energy.

\section{Discussion}

The average strength indices of fiber-reinforced concrete with different reinforcement levels are given in Table 3, and their kinetics are available from Figures 1, 2. It is noteworthy that, when the density is relatively equal, the strength and modulus of elasticity oscillations, which have a clearly pronounced extreme character, are important. That is, the positive effect of disperse reinforcement can only appear in the case of a minimum saturation level of the matrix, in which its brittle failure cannot happen. With a lower fiber content, the prevailing effect of an increase in the heterogeneity of the structure of fiber-reinforced concrete due to reinforcement, the appearance of non-uniformity of the stressed state and, as a consequence, the reduction of the test resistance values. As for the upper limit of effective reinforcement, 
the experimental data do not allow us to judge its level. However, judging by the data of other researchers, its presence is objectively conditioned by the limitation of the volume content of the concrete (matrix) per fiber and ensuring effective interaction between their shells $[1,6$, $7,8]$.

Table 3. Results of tests of the samples being reinforced with macrosynthetic fiber.

\begin{tabular}{|c|c|c|c|c|c|c|}
\hline $\begin{array}{c}\text { Percent } \\
\text { reinforce } \\
\text { ment }\end{array}$ & $\begin{array}{c}\text { Densit, } \\
\mathrm{g} / \mathrm{cm}^{3}\end{array}$ & $\begin{array}{c}\text { Cubic } \\
\text { strength } R, \\
\mathrm{MPa}\end{array}$ & $\begin{array}{c}\text { Prismatic } \\
\text { strength } R_{b n}, \\
\mathrm{MPa}\end{array}$ & $R_{b n} / R$ & $\begin{array}{c}\text { Voltages } \\
\text { corresponding to } \\
\text { the limit of } \\
\text { proportionality } \\
\sigma_{z y} / R_{b n}\end{array}$ & $\begin{array}{c}\text { Modulus } \\
\text { of } \\
\text { elasticit, } \\
\mathrm{MPa}\end{array}$ \\
\hline 0 & 2,231 & 10,8 & 8,57 & 0,79 & 0,84 & 7028 \\
\hline 0,9 & 2,221 & 9,07 & 6,61 & 0,73 & 0,87 & 5052 \\
\hline 1 & 2,228 & 9,30 & 6,79 & 0,70 & 0,87 & 5109 \\
\hline 1,25 & 2,234 & 15,32 & 10,45 & 0,68 & 0,86 & 6676 \\
\hline
\end{tabular}

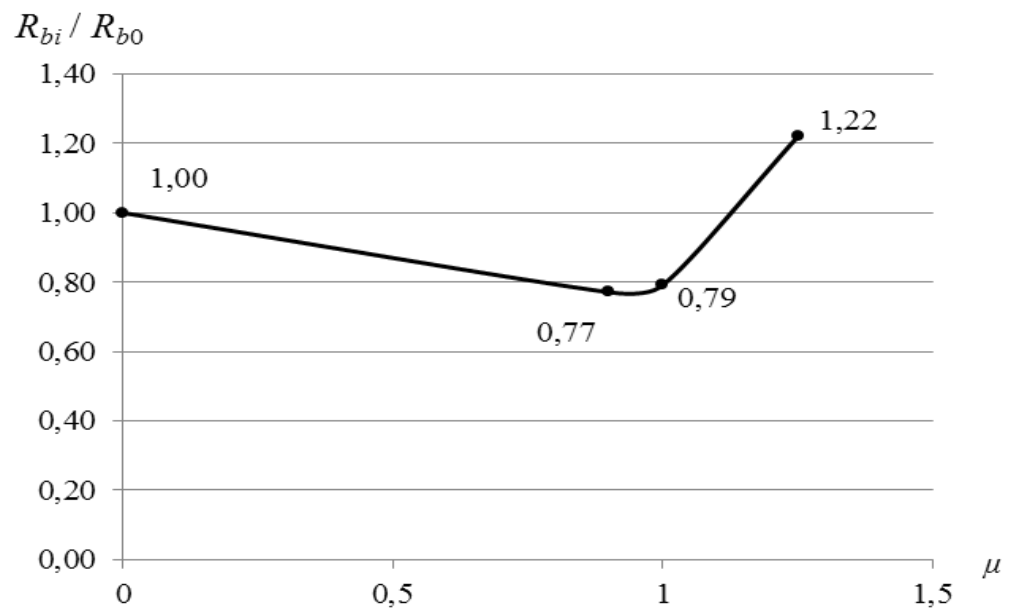

Fig. 1. Kinetics of the strength change from the reinforcement level.

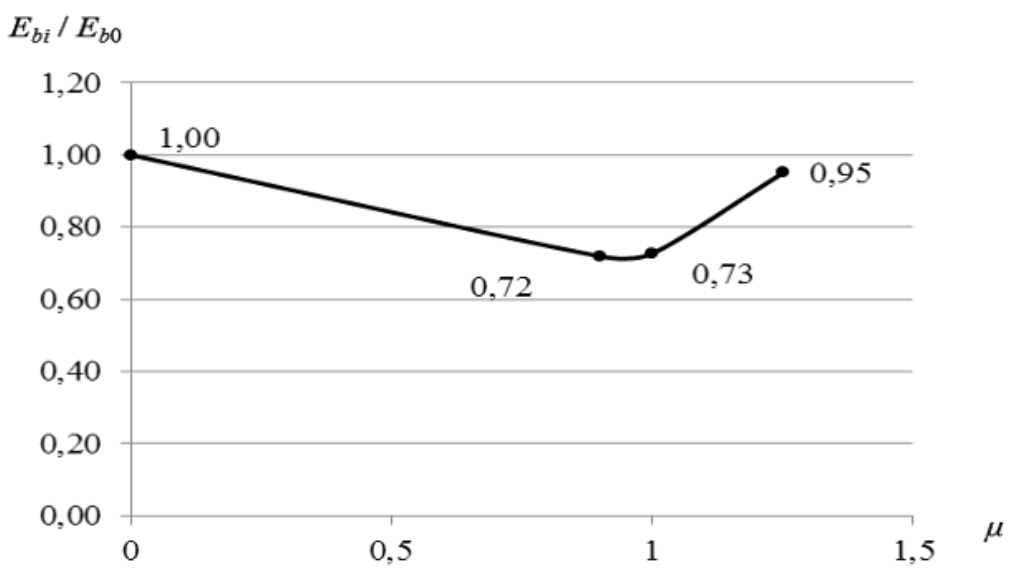

Fig. 2. Kinetics of the modulus of elasticity on $\%$ of the fiber content. 


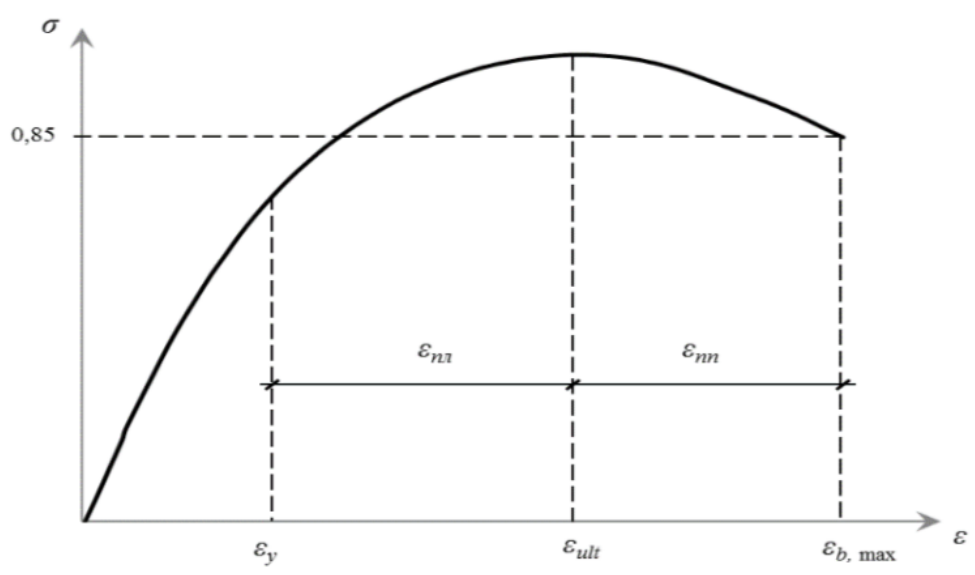

Fig. 3. Compression diagram and components of total deformation of fiber concrete.

The above is confirmed by data on the change in deformation properties of fiber reinforced concrete of various reinforcement levels (Table 4). An increase in the limiting compressibility of fiber-reinforced concrete, implemented under conditions of free deformation $\left(\varepsilon_{u l t}\right)$ is observed. However, its dynamics is essentially non-monotonic, i. e. the intensive growth dramatically increases with reinforcement above the value of the minimum being required for the actual structure of the matrix (in the experiment: 0.9-1\%).

Table 4. Components of the total strain of fibrous concrete.

\begin{tabular}{|c|c|c|c|c|c|c|}
\hline \multirow[b]{2}{*}{ 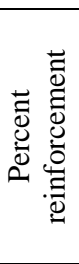 } & \multicolumn{5}{|c|}{ Deformations $\varepsilon \times 10^{5}$, corresponding to } & \multirow[b]{2}{*}{ 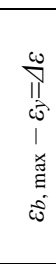 } \\
\hline & $\begin{array}{c}\text { prismatic } \\
\text { strength } \\
\varepsilon_{u l t}\end{array}$ & $\begin{array}{l}\text { the maximum } \\
\text { of } \\
\text { deformations } \\
\text { (the end of the } \\
\text { descending } \\
\text { branch) } \varepsilon_{b, \text { max }}\end{array}$ & $\begin{array}{l}\text { proportionality } \\
\text { limit on the } \\
\text { ascending branch } \\
\varepsilon_{y} \times 10^{5}\end{array}$ & $\begin{array}{c}\text { plastic } \\
\text { component } \\
\varepsilon_{n n} \times 10^{5}\end{array}$ & $\begin{array}{l}\text { the length } \\
\text { of the } \\
\text { descendin } \\
\mathrm{g} \text { branch } \\
\varepsilon n n \times 10^{5}\end{array}$ & \\
\hline 0 & 231 & 337 & 126 & 101 & 109 & 211 \\
\hline 0,9 & 239 & 341 & 148 & 92 & 101 & 193 \\
\hline 1 & 242 & 393 & 144 & 98 & 138 & 248 \\
\hline 1,25 & 271 & 375 & 166 & 105 & 104 & 208 \\
\hline
\end{tabular}

A similar trend is noted in the kinetics of the maximum expected deformations under constrained deformation conditions $\varepsilon_{b}$, max. At the same time, the optimal reinforcement level for this indicator is very low $(0.1-0.3 \%)$.

Of particular interest is the change in the structure of the deformations (Figure 3), which indirectly characterize the physical patterns of the fracture process when compressing fibrous concrete with a different content of fibers. It can be argued that there is a tendency to increase the share of elastic deformations by $7-10 \%$ regardless of the reinforcement factor. The range of plastic deformation is reduced due to a gradual and unstable increase in pseudoplastic deformation. There is an even maximum of constrained strains with reinforcement of $1 \%$.

To analyze the resistance of fiber reinforced concrete with different reinforcement levels, energy costs were determined in the areas of elastic $\left(W_{1}\right)$, plastic $\left(W_{2}\right)$ deformation and the descending branch of the compression diagram $\left(W_{3}\right)$ (Table 5). The obtained data confirm the extreme character of the dependence of the resistance potential on the volume content of reinforcing elements. In this case, the established maximum of the positive reinforcement effect $(1.25 \%)$ does not coincide with the level of optimal fiber saturation corresponding to the best resistance to cracking. 
Table 5. Parameters of the total strain amount of fiber concrete.

\begin{tabular}{|c|c|c|c|c|c|}
\hline \multirow{2}{*}{$\begin{array}{c}\text { Percent } \\
\text { reinforcement }\end{array}$} & \multicolumn{5}{|c|}{ Area, conventional units } \\
\cline { 2 - 6 } & $W_{1}$ & $W_{2}$ & $W_{3}$ & $\Sigma W$ & $W_{1}+W_{2}$ \\
\hline 0 & 505,75 & 816,35 & 870,91 & 2193,00 & 1322,10 \\
\hline 0,9 & 501,92 & 618,79 & 669,36 & 1790,08 & 1120,71 \\
\hline 1 & 477,71 & 640,98 & 886,23 & 1879,91 & 1040,45 \\
\hline 1,25 & 838,68 & 1033,33 & 1025,27 & 2897,27 & 1872,00 \\
\hline
\end{tabular}

It should be noted that the greatest increase in resistance with increasing reinforcement is due to the energy of elastic deformation (about 66\%) with a relatively insignificant increase in the resource of pseudoplastic deformation.

\section{Conclusion}

1. The effectiveness of using the polypropylene fibers as reinforcing concrete elements is characterized by a certain range of bulk saturation, which is predetermined by its structure.

2. The level of optimal reinforcement of fiber-reinforced concrete should be established differentially depending on the operational requirements for load-bearing capacity or crack resistance.

\section{References}

1. F. N. Rabinovich, Composites based on dispersed reinforced concrete. Questions of theory and design, technology, design (ABC Publishing House, Moscow, 2011)

2. D. E. Kapustin, Strength and deformation characteristics of non-removable steel-fiberreinforced concrete formwork as a load-bearing element of reinforced concrete structures (MSSU Publishing House, Moscow, 2015)

3. S. Nostroy, Constructions of transport tunnels from fiber concrete (2013)

4. A. V. Buchkin, Fine-grained concrete of high corrosion resistance, reinforced with a thin basalt fiber (Research and Development Center "Construction", Moscow, 2011)

5. J. R. Romualdi, J. A. Mandel, ACI Jornal, 61, 6, 657 (1964)

6. T. B. Morgun, Izvestiya Vuzov. Construction, 8, 58-60 (2003)

7. A. Peled, M. F. Cyr, S. P. Shah, ACI Material Journal, 97, 5, 509-517 (2000)

8. C. D. Johnston, Properties of Steel Fibre Reinforced Mortar and Concrete (The Construction Press, Lancaster, London, 1980)

9. I. G. Korneeva, N. A. Emelyanova, Proceedings of Universities. Investment. Construction. Real Estate, 4(19), 122-128 (2016) 